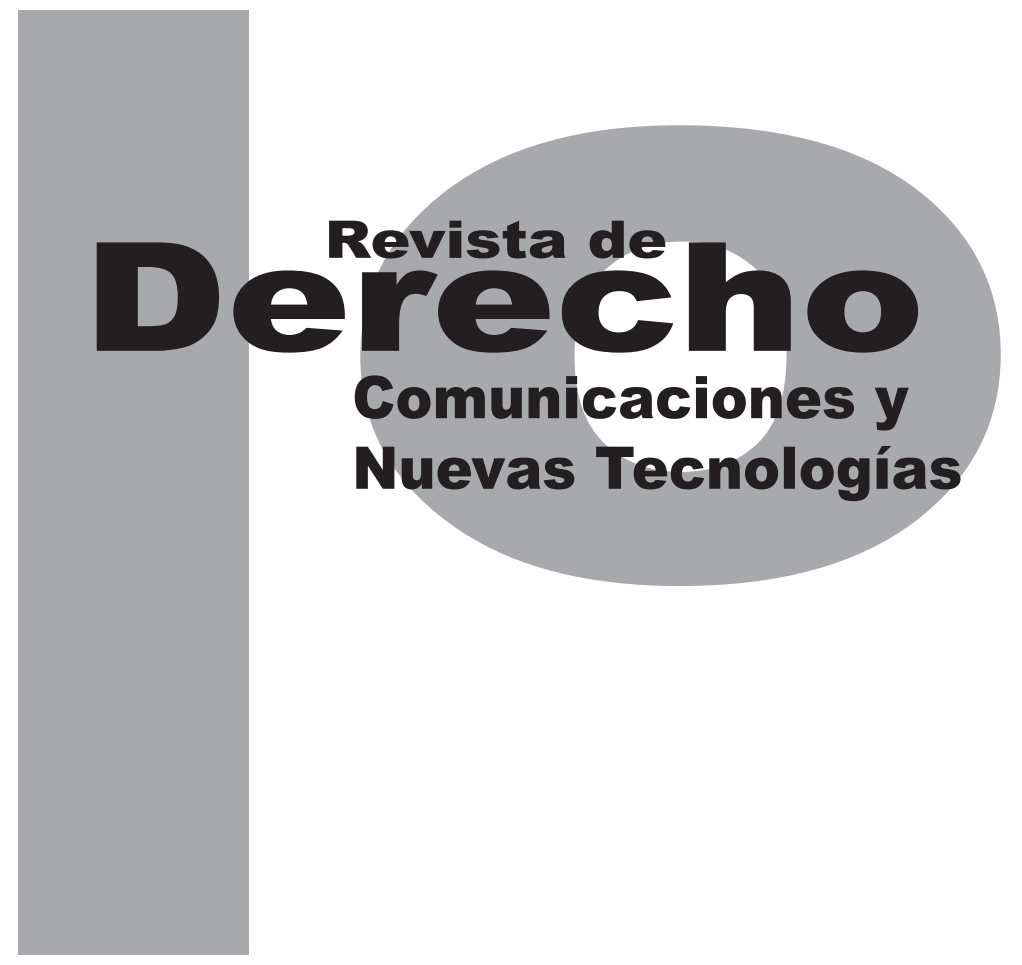

\title{
EL HÁBEAS DATA A VEINTE AÑOS DE SU INCORPORACIÓN EN LA CONSTITUCIÓN ARGENTINA
}

\author{
OsCAR R. PucCinelLI
}

Artículo de investigación científica y tecnológica

DOI: http://dx.doi.org/10.15425/redecom.13.2015.02

\author{
Universidad de los Andes \\ Facultad de Derecho
}

Revista de Derecho, Comunicaciones y Nuevas Tecnologías

No.13, Enero - Junio de 2015. ISSN 1909-7786 


\section{El hábeas data a veinte años de su incorporación en la Constitución argentina}

\section{Resumen}

En Argentina, el hábeas data como acción y como proceso fue introducido formalmente en la reforma a la Constitución operada en 1994. El art. 43 constitucional fue reglamentado en 2000, por la Ley 25.326, de protección de los datos personales, que tiene sectores aplicables en toda la República y otros solo en el plano federal. A veinte años de la reforma, poco queda de la literalidad de la norma constitucional, que ha sido completamente superada no solo por efecto de la labor reglamentaria, sino por una sólida corriente interpretativa e integrativa de la mejor doctrina y de la jurisprudencia, que supo superar aquella literalidad para desplegar la figura al máximo de sus posibilidades, a partir también de cierto activismo judicial. El trabajo presenta precisamente los contornos actuales de la cláusula constitucional, con sus adiciones y sustracciones, fruto de toda esa evolución.

Palabras clave: hábeas data, reforma constitucional argentina de 1994, Ley federal de protección de datos, activismo judicial, interpretación e integración.

\section{Habeas data inclusion in the Constitution of the Argentine Nation. Twenty years later}

\section{Abstract}

The habeas data as a constitutional action and as a constitutional process was formally introduced in the federal Constitution amendment who took place in 1994. The article 43 was regulated in 2000 by law 25.326 (the personal data protection federal law), which is applicable in some sectors throughout the Republic and in others only at federal level. 20 years after this constitutional inclusion, too little portions of its literalness are still standing. It has been completely overcome based on further regulations and a very particular and strong interpretative and integrative labor of the better doctrine and jurisprudence that provided the maximum possible extent to the figure, in a clear sign of judicial activism. The current work presents precisely the actual contours of the constitutional clause, with additions and subtractions that resulted of all these developments.

Keywords: habeas data, 1994's Argentinian constitutional amendment, Federal data protection law, judicial activism, interpretation and integration, twenty years after its inclusion in the argentinian Constitution.

\section{O habeas data a vinte anos de sua incorporação na Constituição argentina}

\section{Resumo}

$\mathrm{Na}$ Argentina, o habeas data como ação e como processo foi introduzido formalmente na reforma da Constituição operada em 1994. 0 art. 43 constitucional foi regulamentado em 2000, pela Lei 25.326, de proteção dos dados pessoais, que tem setores aplicáveis em toda a República e outros só no plano federal. A vinte anos da reforma, pouco fica da literalidade da norma constitucional, que tem sido completamente superada não só por efeito do labor regulamentário, senão por uma sólida corrente interpretativa e integrativa da melhor doutrina e da jurisprudência, que soube superar aquela literalidade para desdobrar a figura ao máximo de suas possibilidades, a partir também de certo ativismo judicial. 0 trabalho apresenta precisamente os contornos atuais da cláusula constitucional, com suas adições e subtrações, fruto de toda essa evolução.

Palavras-chave: habeas data, reforma constitucional argentina de 1994, Lei federal de proteção de dados, ativismo judicial, interpretação e integração. 


\title{
El hábeas data a veinte años de su incorporación en la Constitución argentina*
}

\author{
Oscar R. Puccinelli**
}

\section{SUMARIO}

Introducción. El iter doctrinario-normativo hacia la consagración constitucional de la figura - I. EL TEXTO CONSTITUCIONAL Y SUS “MODIFICACIONES" REGLAMENTARIAS Y JURISPRUDENCIALES - A. “Toda persona podrá..." - B. "interponer esta acción..." - C. "para tomar conocimiento de los datos a ella referidos y de su finalidad" - D. "que consten en registros o bancos de datos públicos, o los privados destinados a proveer informes" - E. "y en caso de falsedad o discriminación" - F. "para exigir la supresión, rectificación, confidencialidad o actualización de aquéllos" - G. "No podrá afectarse el secreto de las fuentes de información periodística" - III. CONCLUSIONES - Referencias.

Cómo citar este artículo: Puccinelli, O. R. (Junio, 2015). El hábeas data a veinte años de su incorporación en la Constitución argentina. Revista de Derecho, Comunicaciones y Nuevas Tecnologías, 13. Universidad de los Andes (Colombia)

** Abogado, egresado de la Universidad Nacional de Rosario (Argentina). Doctor en Derecho Constitucional por la Universidad de Buenos Aires (Argentina). Docente investigador categorizado en el sistema nacional argentino. Profesor de Derecho Constitucional y de Derecho Procesal Constitucional, Universidades Católica Argentina y Nacional de Rosario. Doctor y profesor honoris causa de varias universidades peruanas. Juez de la Cámara de Apelación en lo Civil y Comercial de Rosario (Argentina). 


\section{Introducción. El iter doctrinario -normativo hacia la consagración constitucional de la figura}

La acción de hábeas data fue incluida en la última reforma a la Constitución argentina, producida en 1994, oportunidad en la cual se la incorporó en el art. 43, tercer párrafo, sin denominárselo de este modo y sin dársele la autonomía que merecía respecto de la figura del amparo, precisamente por cuestiones vinculadas a la falta de habilitación expresa para su incorporación en la Ley $n .{ }^{\circ} 24.309$, declarativa de la necesidad de la reforma constitucional que fijó los límites temáticos de la labor reformadora. ${ }^{2}$

\section{La cuestión igualmente suscitó algunas dudas} doctrinarias acerca de su constitucionalidad, ${ }^{3}$ pero dado que formalmente este nuevo instituto fue ubicado como un subtipo de amparo, figura que sí se encontraba autorizada expresamente en dicha norma habilitante, tales eventuales planteos nunca se materializaron en una decisión judicial favorable. ${ }^{4}$

2 Pese a que, como se dijo, ninguna referencia hacía la Ley 24.309 a la figura del hábeas data, fueron presentados 27 proyectos en la Convención. Para un análisis detallado de los debates, ver Masciotra (2003, págs. 74 a 83).

3 Esta falta de habilitación expresa ha llevado a algunos autores, especialmente a partir del caso Fayt, Carlos S. c/Estado nacional s/ proceso de conocimiento (LL, 1999-E-305 y ED, 184-998), en el cual la Corte nacional declaró la inconstitucionalidad del art. 99 de la Constitución nacional ( $\mathrm{CN}$ ) respecto de la fijación del límite de edad para permanecer con estabilidad en el cargo, a advertir que el art. 43, párr. $3^{\circ}$, es uno de los que entran en estado de sospecha y pueden ser declarados inconstitucionales por incurrir también en idéntica violación (Bianchi, 2000).

$4 \quad$ Explica al respecto Sacristán (2007): “Un repaso de la obra de la Convención Nacional Constituyente de 1994 permite inferir que la cuestión de la inclusión del hábeas data como especie de amparo no fue tan pacífica como podría imaginarse. Desde cierta perspectiva, se percibe también la preocupación por hallar, en la ley declarativa de la
La regla constitucional encontró eco inmediato en varios intentos reglamentarios que dieron primeramente origen a la sanción, el 27/11/96, del proyecto de Ley n. ${ }^{\circ} 24.745$, que nunca entró a regir pues fue totalmente vetado, y finalmente se materializó al dictarse, en 2000 , la -ahora parcialmente vetada- Ley 25.326, que se reglamentó de inmediato a través del Decreto

necesidad de la reforma, la habilitación requerida so pena de nulidad (art. 6, Ley 24.309).

Así, si se consideran los proyectos oportunamente arrimados, se detectan los que visualizaban al hábeas data como una especie de hábeas corpus (cita los proyectos obrantes en la colección "Obra de la Convención Nacional Constituyente 1994", Centro de Estudios Constitucionales y Políticos - Ministerio de Justicia de la Nación República Argentina, La Ley, Buenos Aires, 1995, t. II —Proyectos de reforma a la Constitución, expedientes $\mathrm{N}^{\circ} 1$ a 909 , publicados como capítulo IV-y t. III —Proyectos de reforma a la Constitución, expedientes $\mathrm{N}^{\circ} 910$ a 1593, publicados como capítulo IV—, y en particular refiere a los mencionados en t. II, p. 822, 1840 y 1849); o como una especie de amparo (remite a los proyectos obrantes en el t. IV, p. 2019; t. II, p. 1705; 1828 y 1831 y t. III, p. 2700); o como género -no como especie de amparo o amparo especial- (cita los proyectos obrantes en el t. III, ps. 2641/2645; t. II, ps. 1745/1746; t. II, p. 1008 y t. II, ps. 1258/1259).

Por ello, puede decirse que la cuestión de dicha inclusión no pasó desapercibida para el constituyente de 1994. Ello dota de pleno sentido opiniones que oportunamente se volcaron en el debate, cuya importancia no puede ser morigerada: "Esta Convención reformadora tiene el deber histórico de hacer efectiva esa protección a la libertad humana mediante la consagración en la letra constitucional de lo que se ha dado en llamar las garantías constitucionales: el hábeas corpus y el amparo" (debate del 12 de agosto de 1994); "Si bien estamos habilitados por la ley 24.309, que determina y declara la necesidad de la reforma, el hábeas data no estaba contenido o contemplado como un instituto sino que se desprende de una de las modalidades del amparo" (debate del 11 de agosto de 1994); "Pienso que dada la obvia conexión entre el amparo, el hábeas corpus y el hábeas data — que participan de una misma naturaleza, constituyendo los dos últimos un subtipo del primero según el pensamiento de Gimeno Sendra-, no cabe duda de que establecida la posibilidad de declarar la inconstitucionalidad en el amparo, la misma rige para ambos institutos que constituyen subtipos del primero" (debate del 16 de agosto de 1994). Y más trascendente aún resulta esta reflexión de un convencional constituyente: "Creo que este instituto no está habilitado - aunque se dirá que lo está porque es una variedad de amparo, entiendo que es una cuestión opinable-y los países que lo contienen, como el caso de España, lo remiten a la ley, y el de Brasil se refiere a datos oficiales o públicos" (debate del 16 de agosto de 1994).

De tal modo, quedó propuesta la interpretación conforme la cual el hábeas data era una especie de amparo, única manera de sustentar su inclusión en el texto constitucional a la luz del alcance de la declaración de la necesidad de la reforma constitucional, que solo enumeraba, además de la acción de hábeas corpus, la acción de amparo (debate del 16 de agosto de 1994)" (Sacristán, 2007, págs. 501 y ss.). 
1558/01 y fue modificada ocho años más tarde por la Ley 26.343, que introdujo un blanqueo de morosos que ya estaba previsto de forma similar por el vetado art. 47 de la Ley $25.326 .^{5}$

La regla legal así adoptada rige en todo el país, pero de manera parcial, porque si bien todos los principios generales relativos al tratamiento de los datos personales en el sector público y en el sector privado son de aplicación en todo el territorio nacional, el control administrativo y judicial federal por ella pergeñado es de alcance limitado (el administrativo, desde que las facultades del órgano de control -la Dirección Nacional de Protección de Datos Personales- no abarca todos los sujetos que realicen el tratamiento de datos personales, y el judicial, desde que solo reglamenta la acción y el proceso de hábeas data para el ámbito de la justicia federal). ${ }^{6}$

5 Con anterioridad, puede detectarse una serie de antecedentes que se desplegaron especialmente durante el período inmediatamente posterior a la reinstalación del sistema democrático, y ello tanto en el ámbito nacional como en el provincial. En el nacional, a través de distintos aportes doctrinarios y proyectos legislativos que si bien no eran específicamente destinados a regular la garantía se referían a aspectos íntimamente vinculados a ella. En el provincial, a partir de las reformas constitucionales operadas desde entonces, donde si bien no se incorporó la figura con ese nombre también se refirieron a problemas vinculados a ella, y solo en la Constitución de Río Negro se reguló un similar "amparo informático". La cuestión fue considerada, por ejemplo, en el Proyecto de Unificación Legislativa Civil y Comercial de la Nación, de 1987, que consagraba expresamente la reparabilidad de los daños sufridos por las personas, de existencia visible en sus derechos a la intimidad personal y familiar y al respeto de su honra o reputación; limitaba la acumulación de datos de carácter personal en registros informatizados y regulaba los derechos de los titulares de datos personales (arts. 110 a 116). También fue considerada en el proyecto elaborado por la Comisión designada por el Poder Ejecutivo nacional mediante el Decreto 468/92, donde se trataba la cuestión en la sugerida reforma al Libro $2^{\circ}$ del Código Civil.

Que rija limitadamente la ley con relación al proceso de hábeas data, por ceñirse a la justicia federal, en modo alguno significa que no exista similar protección en la justicia ordinaria, puesto que los estados federados están obligados a darle vigencia a esta garantía, la hayan o no reglamentado, tal como lo destacara la Corte nacional en Urteaga, Facundo Raúl c/Estado Nacional -Estado Mayor Conjunto de las F.F.A.A.— s. Amparo Ley 16.986 (CSJN, 15/12/98, fallos: 321:2767).

\section{EL TEXTO CONSTITUCIONAL Y SUS "MODIFICACIONES" REGLAMENTARIAS Y JURISPRUDENCIALES}

La cláusula constitucional, como se adelantó, se ubica en el tercer párrafo del art. 43 constitucional -luego de que se regularan, en los dos párrafos anteriores, el amparo individual y el amparo colectivo, y antes del hábeas corpus $-y$ reza:

Toda persona podrá interponer esta acción para tomar conocimiento de los datos a ella referidos y de su finalidad, que consten en registros o bancos de datos públicos, o los privados destinados a proveer informes, y en caso de falsedad o discriminación, para exigir la supresión, rectificación, confidencialidad o actualización de aquéllos. No podrá afectarse el secreto de las fuentes de información periodística.

Veamos qué queda, y cómo, del texto constitucional luego de veinte años de su aplicación.

\section{A. "Toda persona podrá..."}

La norma constitucional, al no diferenciar, deja margen para la habilitación tanto a las personas físicas como a las de existencia ideal, y de hecho ha sido utilizada indistintamente por ambos tipos de legitimados, tal como surge, v. gr., de la jurisprudencia de la Corte nacional, que resolvió varios hábeas data articulados por personas de existencia ideal, v. gr., casos Matimport (CSJN, 9/3/99, fallos, 322:262) y Cía. Azucarera Concepción S. A. (CSJN, 7/2/06, C. 37. XL.). 
La Ley 25.326, en sintonía con esta habilitación y siguiendo la normativa española que fuera su fuente principal (la LORTAD $^{7}$ de 1992), establece en el art. $1^{\circ}$, párr. $2^{\circ}$, que sus disposiciones "serán aplicables, en cuanto resulte pertinente, a los datos relativos a personas de existencia ideal".

El giro "en cuanto resulte pertinente" no puede entenderse como limitación de la disposición constitucional, sino solo como una prevención acerca de que las personas de existencia ideal no gozan de todos los derechos que pueden predicarse de las personas físicas, o en algunos casos son meramente asimilables a aquellos pero no idénticos (v. gr., no gozan estrictamente del derecho a la vida o a la salud, ni tampoco poseen dignidad o intimidad, aunque sí titularizan una zona de reserva o secreto, como puede ser el secreto industrial; tampoco gozan de honor, pero sí de reputación, por ejemplo, comercial, etc.).

Más allá de lo expuesto, la habilitación se debe ponderar desde otro ángulo, esto es, desde el bien jurídico tutelado, el cual, como ya lo explicitaremos, es el derecho a la protección de los datos personales, y de tal suerte poco importa si quien pretende corregir un dato es una persona física o de existencia ideal, pues debe presumirse que cualquier dato tratado en contra de los principios del derecho de la protección de datos tiene aptitud para causar un perjuicio a otro $u$ otros derechos, independientemente de la natu-

7 Ley Orgánica de Regulación del Tratamiento Automatizado de los Datos de Carácter Personal. raleza y extensión del derecho que pudiera encontrarse vulnerado.

Por último, y como se verá luego, la referencia a "toda persona" resulta insuficiente para analizar la legitimación activa para interponer un hábeas data, pues por efecto de la ubicación de esta garantía como subtipo de amparo dicha legitimación se amplía, aunque limitadamente, al defensor del pueblo, a las asociaciones sectoriales y al Ministerio Público, a partir de lo dispuesto por los arts. 43 (segundo párrafo), 86 y 120 de la Constitución nacional.

\section{B. "interponer esta acción..."}

La regla se refiere, inequívocamente, a la acción de amparo que previamente reguló. Recordemos que haberla independizado constitucionalmente de esta o del hábeas corpus habría traído como consecuencia su inconstitucionalidad por falta de habilitación legal, tal como lo destacara el convencional Díaz en su intervención en el recinto de la Convención, donde se expresó que ni siquiera se rotuló por su nombre para evitar cualquier cuestionamiento posterior. Por ello la regla no utiliza la voz hábeas data y se remite tanto al primer párrafo -versión "individual” o "general" del amparo- como al segundo -“amparo colectivo"-, dentro del cual la Corte nacional, en Halabi, Ernesto c/ P.E.N. Ley 25873 dto. 1563/04 (fallos 332:111), encontró alojada también a la "acción de clase" en defensa de los "derechos individuales homogéneos".

Menciona Sacristán al referirse a la posición que reduce al hábeas data a un subtipo de amparo: 
Esta interpretación no es unánime pues se ha visualizado a la acción del párr. $3^{\circ}$ del art. 43 , $\mathrm{CN}$, como una acción específica, genérica, ajena al régimen de la acción de amparo o, al menos, ajena a la aplicabilidad de los recaudos legislativamente asociables a aquel (Suprema Corte de la Pcia. de Mendoza, fallo del 17/11/1997, “JA" 1998-III-24, cit. en Salgado Alí Joaquín, Verdaguer Alejandro C., "Juicio de amparo y acción de inconstitucionalidad”, 2da. ed., Astrea, Buenos Aires, 2000, esp. p. 327).

La cuestión no es menor. Considérese, tan solo, que si se concibe a la acción de hábeas data como una especie de acción de amparo, estaría sujeta a todos los recaudos aplicables a esta última. Así, por ej., se podría exigir la presencia de arbitrariedad o ilegalidad manifiesta del art. $1^{\circ}$ de la ley 16.986 en el obrar de la base de datos; se podría llegar a requerir el agotamiento bajo el art. $2^{\circ}$, inc. a), de dicha ley (recaudo que ha sido visualizado como atenuado mas no como eliminado o derogado orgánicamente; véanse las reflexiones de Cassagne, Juan Carlos, "La tutela judicial efectiva. Incompatibilidad con el dogma revisor y con la regla del agotamiento de la vía administrativa", en Cassagne, Juan Carlos, "Fragmentos de Derecho administrativo. Entre la justicia, la economía y la política", Hammurabi, Buenos Aires, 2003, págs. 131/155, esp. págs. 148/149); entre otras posibilidades" (Sacristán, 2007, págs. 501 y ss.).

En este contexto, la remisión a la acción de amparo generó alguna confusión inicial respecto de la exigibilidad de ciertos recaudos típicos de aquella, en especial los restrictivos, como la necesidad de que exista una conducta manifiestamente arbitraria o ilegal y que no esté disponible otro medio judicial más idóneo.
Adicionalmente, y como también fue objeto de disputa en el amparo ya que ello no se reguló en el texto constitucional, se discutió sobre si la acción era susceptible de caducar, cuestión que amerita una respuesta negativa, pues emerge claramente la inexigibilidad del recaudo tanto de lo resuelto por la Corte en Urteaga ${ }^{8}$ como del hecho que, en general, las conductas atacables por el hábeas data normalmente producen lesiones continuas que nunca permiten iniciar el cómputo de tal eventual caducidad.

Con respecto de las dos primeras cuestiones mencionadas supra, y dada la especificidad de la acción, se ha entendido que no son recaudos de admisibilidad ni la acreditación de la existencia de otro medio judicial más idóneo -en especial porque precisamente el hábeas data ha sido diseñado como el medio más idóneo respecto del amparo general para la protección de los datos personales- ni la existencia de arbitrariedad o ilegalidad manifiesta, desde que precisamente se trata de evaluar la compatibilidad legal del tratamiento. Esto último, pese a cierta confusión que surgió de lo resuelto por la Corte nacional en Lascano Quintana (CSJN, 06/03/2001), que luego fue matizada en Martínez, Matilde (CSJN, 5/4/05).

Adentrándose en esta temática, indica Kemelmajer de Carlucci:

La posición asumida por el texto constitucional (el hábeas data es una especie de amparo) no

8 En este se ocupó en 1998 de un caso ocurrido en 1976 y cuya acción se instauró transcurridos los 15 días desde que se tuvo conocimiento de la lesión y de la entrada en vigencia de la norma constitucional. 
implica aceptar que todo lo regulado por la ley de amparo sea aplicable al hábeas data; en efecto, el objeto perseguido procesalmente difiere en ambos casos; por ejemplo se ha afirmado que para la procedencia del hábeas data no se requiere, en principio, arbitrariedad o ilegalidad manifiestas dado que procede ante la mera falsedad en el contenido de los datos o la discriminación que de ellos pudiere resultar. ${ }^{9}$

Por su parte, Bidart Campos sostuvo, con anterioridad a la aprobación de la Ley de Protección de Datos Personales (LPDP), que ordinariamente debe eximirse la presencia de arbitrariedad o ilegalidad manifiesta en el acto respecto del cual se ejerce el hábeas data "porque resulta evidente que si - por ejemplo- se pretende tomar conocimiento de datos personales, suprimirlos, rectificarlos o actualizarlos, puede no ocurrir aquella arbitrariedad o ilegalidad en la recopilación o acumulación que de ellos hizo y posee de buena fe el registro o el banco" (1997, pág. 756).

En la misma línea se encuentra Gelli (2003, pág. 410) y también Bazán (2000), quien sostiene que, si nos apegamos al texto expreso de la norma, la Constitución ha elaborado supuestos específicos para el funcionamiento de la acción que postergarían a aquellos: la falsedad de la información o su efecto discriminatorio. De otro lado -explica- en el hábeas data hay dos momentos bien distintos: el de acceso a los datos, y el de intervención sobre la información alma-

9 Su voto en SC Mendoza, 17/11/97, "Costa Esquivel, Oscar A. c/Co.de. me. s/acción de hábeas data", con nota de Jorge Vanossi, "Un caso de hábeas data: entre el derecho procesal y el derecho constitucional". ED, 176-350. cenada. En el primer caso, bastará acreditar ser el titular de la información y, en el segundo, "quizás sí sea menester que el afectado acredite la falsedad, el uso discriminatorio de la información o el perjuicio que le irroga, pero nunca antes de tener acceso a los datos, ya que mal puede acreditar algo que no le consta" (Bazán, 2000, págs. 226-257).

Al evaluar esta cuestión, afirma Palazzi (1998) que del análisis de las normas de la ley de amparo y de las primeras tendencias jurisprudenciales habidas en materia de hábeas data surgía claramente que una aplicación estricta de las reglas del amparo en muchos casos tornaba al proceso en inoperante, por cuanto:

Los requisitos de interponer la acción dentro del plazo legal establecido o la arbitrariedad exigida al acto lesivo conspiran contra el éxito de esta acción... En esta misma línea, Altmark y Molina Quiroga han expresado que asimilar el hábeas data a la acción de amparo implica correr el riesgo de desvirtuar la finalidad del instituto.

En el plano jurisprudencial, la Corte nacional ha tratado esta cuestión. Primeramente se observa que ha puntualizado que, a diferencia del amparo, mediante el hábeas data "no se intenta hacer cesar ningún acto u omisión lesivo de derechos y garantías manifiestamente ilegítimo o arbitrario, sino que se solicita el acceso a datos" (csjn, 15/12/98), pero luego estableció por vía de obiter, en Lascano Quintana, la vigencia de este requisito (Puccinelli, 2004, pág. 572), al sostener, sin ninguna claridad ni convicción y por vía de remisión al dictamen del procurador 
general, que la interpretación realizada en baja instancia:

Como bien lo destaca el señor procurador fiscal exorbita el texto constitucional que prevé una medida de tal naturaleza, ante actos de ilegalidad o arbitrariedad manifiesta, solo para los casos de falsedad o discriminación, imputando incorrectamente al procurador haber sostenido una supuesta exigencia proveniente de la Constitución de arbitrariedad o ilegalidad manifiesta y la limitación del radio de acción de la figura derivada del texto constitucional a los casos de falsedad y discriminación (csjn, 06/03/2011).

Esta errada posición fue matizada claramente en Martínez, donde ya rectificando el rumbo la Corte expresó que, de conformidad con los arts. 4 , incs. $4^{\circ}$ y $5^{\circ}, 26$ y 33 de la Ley 25.326 , los datos registrados por las empresas que prestan servicios de información crediticia deben ser exactos y completos; vale decir, no es suficiente con que la información haya sido registrada y transmitida sin "arbitrariedad manifiesta", sino que tiene que ser precisa (cssn, 5/4/05).

Como lo explica Sagüés al expedirse por la supletoriedad del hábeas data:

En “Lascano Quintana” la Corte Suprema convalidó la tesis de exigir la presencia de arbitrariedad o ilegalidad manifiesta como presupuesto para la admisión del hábeas data, pero más tarde -en "Martínez"- entendió que tal recaudo no es actualmente requerible, porque la ley 25.326, reglamentaria de tal acción, no lo demanda...

No obstante lo dicho, debe tenerse muy en cuenta que, por el daño inmediato, grave e irre- parable que habitualmente generan para las personas los errores, omisiones, inserciones o divulgaciones indebidas en los registros y bases de datos públicos y privados (cuya difusión, muchas veces por Internet, es instantánea y prácticamente universal, y cuya corrección también debería ser inmediata), el tránsito regular de otros remedios procesales diferentes al hábeas data para atacar a esos actos lesivos puede resultar engorroso, tardío y, a la postre, de dudosa eficacia, frustrándose por ello el objetivo propio de la tutela de los derechos a los que se refiere el hábeas data. En resumen, con mucha frecuencia, el uso directo de este último, aun cuando en principio sea concebido como acción supletoria, será perfectamente posible (2009, págs. 623-624).

Desde mi punto de vista, la cuestión tenía trascendental importancia antes del dictado de la Ley 25.326, pero luego de su entrada en vigencia quedó algo relativizada, ya que al estar referidas en tal norma las reglas principales para el tratamiento de los datos personales, la mayoría de los supuestos de tratamiento ilegal surge claramente -con evidencia, "manifiestamente"de la violación a tales reglas, y el tratamiento arbitrario puede aparecer también de manera manifiesta, v. gr., de la negativa a realizar determinadas operaciones que el legitimado activo está habilitado a solicitar en función de los principios del derecho a la protección de datos, pero que no estén contenidas expresamente en la ley (v. gr., determinados supuestos de caducidad del dato negativo, solicitudes de inclusión en un banco de datos, etc.). ${ }^{10}$

10 En esta inteligencia, expresa Carranza Torres concordando con Ruiz Martínez: "El requisito de arbitrariedad e ilegalidad manifiesta, 


\section{C "para tomar conocimiento de los datos a ella referidos y de su finalidad"}

Si bien este sector de la norma se refiere al objeto primario del habeas data - conocer los datos propios y la finalidad del sistema de información en el que se encuentran almacenados- que luego complementará poco más adelante con otras acciones consecuentes (supresión, rectificación, confidencialización o actualización), cabe primeramente vincularlo con la cuestión de la legitimación activa.

Del texto surge claro que está habilitada para interponer la acción la persona a la cual los datos en cuestión se refieren (el "titular" del dato, en los términos de la Ley 25.326), y también puede concluirse que, implícitamente, se estaría inhibiendo a terceros por lo menos de interponer la acción para tomar conocimiento de los datos que no les son propios.

En efecto, al habilitarse a toda persona a accionar por los "datos a ella referidos" pareciera cerrarse la legitimación solo al "afectado" del primer párrafo del art. 43 constitucional, pero precisamente como lo ha reconocido la Corte en Urteaga (csjn, 15/12/98), puede haber otros "afectados" distintos del titular de los datos por el tratamiento indebido, que no son estrictamente terceros en el completo sentido de la

mencionado en el primer párrafo del art. 43 de la Const. nacional, debe interpretarse dentro de la naturaleza de esta especial acción, y entenderse comprendido dentro del concepto de información inadecuada, violatoria de derechos del individuo. En este sentido, entendemos que cuando la información es violatoria de derechos ya contiene la arbitrariedad e ilegalidad manifiesta que se requieren para el inicio de la acción de amparo" (2001, pág. 162, con cita de Ruiz Martínez, 1998, pág. 245). palabra, por ejemplo, por su proximidad parental con el titular de los datos desaparecido, ${ }^{11}$ ya que estos se ven también profundamente afectados en sus derechos más elementales. Así, en situaciones extremas, puede ser excepcionado el principio de exclusividad en el acceso a los datos propios, tal como lo reconoció la propia Ley 25.326 al tomar esta situación excepcional y regularla, habilitando (con ciertos errores de redacción que generan alguna confusión), ${ }^{12}$ a sucesores y parientes próximos de las personas fallecidas.

La legitimación para ejercer la acción también se ve ampliada por la propia remisión que el tercer párrafo del art. 43 hace respecto de la acción regulada en los dos párrafos anteriores, de modo que cabe recurrir a una interpretación amplia que respete la restricción mencionada de acceso excepcional a los datos no propios y entonces, con esa limitación, podrán el defensor del pueblo (que ya está habilitado para actuar como coadyuvante en un hábeas data individual por el art. 34 de la Ley 25.326), el Ministerio Público y las asociaciones sectoriales articular estos procesos, por ejemplo, para conjurar lesiones a escala donde, v. gr., el banco de datos

11 En el caso, se legitimó al hermano de un desaparecido a requerir datos sobre el paradero de este a fin de dar satisfacción, entre otros, al derecho a la verdad, al duelo, a enterrar a los muertos.

12 Art. 14.- (Derecho de acceso). "1. El titular de los datos, previa acreditación de su identidad, tiene derecho a solicitar y obtener información de sus datos personales... 4. El ejercicio del derecho al cual se refiere este artículo en el caso de datos de personas fallecidas le corresponderá a sus sucesores universales".

Art. 34.- (Legitimación activa). "La acción de protección de los datos personales o de hábeas data podrá ser ejercida por el afectado, sus tutores o curadores y los sucesores de las personas físicas, sean en línea directa o colateral hasta el segundo grado, por sí o por intermedio de apoderado..." 
en cuestión trate datos sensibles como los de religión, sin estar habilitado para ello. No será necesario, en estos casos, que los legitimados distintos del afectado conozcan puntualmente los datos que les conciernen, siendo suficiente la articulación del hábeas data a fin de eliminar de la base los datos de religión de todos los afectados.

Vale a este respecto traer a colación lo expresado por la Corte nacional en Halabi, cuando expresó, en los considerandos 19 y 20, que:

a) en otras ocasiones la Corte ha advertido que el propio texto constitucional autoriza el ejercicio de las acciones apropiadas para la defensa de intereses colectivos con prescindencia de las figuras expresamente diseñadas en él o en las normas procesales vigentes,

b) la protección judicial efectiva no se reduce únicamente al amparo stricto sensu sino que es susceptible de extenderse a otro tipo de remedios procesales de carácter general como el hábeas corpus colectivo (Cels o Verbitsky, faIlos: 328:1146, considerandos 15 y 16), pues es lógico suponer que si se reconoce la tutela colectiva de los derechos citados en el párrafo segundo del art. 43, con igual o mayor razón la Constitución otorga las mismas herramientas a un bien jurídico de valor prioritario y del que se ocupa en especial, no precisamente para reducir o acotar su tutela sino para privilegiarla;

c) dada la naturaleza de los derechos en juego en este caso, la calidad de los sujetos integrantes del colectivo y el principio de interpretación de las normas más allá de su letra, y conforme a la finalidad perseguida y la dinámica de la realidad, un afectado, el defensor del pueblo y determinadas asociaciones pueden deducir, en los términos del segundo párrafo del art. 43, una acción colectiva con análogas características y efectos a la existente en el derecho norteamericano (Cels, fallos: 328:1146, considerando 17 y sus citas);

d) ante la ausencia de pautas adjetivas mínimas que regulen la materia, es indispensable formular algunas precisiones a fin de que frente a la utilización que en lo sucesivo se haga de la figura de la "acción colectiva" delineada en el fallo se resguarde el derecho de la defensa en juicio, como modo de evitar que alguien pueda verse afectado por una sentencia dictada en un proceso en el que no ha tenido la posibilidad efectiva de participar.

Así, la admisión formal de toda acción colectiva requiere la verificación de recaudos elementales que hacen a su viabilidad, tales como: 1) la precisa identificación del grupo o colectivo afectado; 2) la idoneidad de quien pretenda asumir su representación; 3) la existencia de un planteo que involucre, por sobre los aspectos individuales, cuestiones de hecho y de derecho que sean comunes y homogéneas a todo el colectivo; 4) que se arbitre en cada caso un procedimiento apto para garantizar la adecuada notificación de todas aquellas personas que pudieran tener un interés en el resultado del litigio, como manera de asegurarles tanto la alternativa de optar por quedar fuera del pleito como la de comparecer en él como parte o contraparte; 
5) la implementación de adecuadas medidas de publicidad orientadas a evitar la multiplicación o superposición de procesos colectivos con un mismo objeto, a fin de aventar el peligro de que se dicten sentencias disímiles o contradictorias sobre idénticos puntos.

Ya con respecto a la acción de clase instaurada por Halabi, la Corte expresó que en el caso:

a) se verifica un hecho único - la normativa en cuestión- que causa una lesión a una pluralidad relevante de derechos individuales; la pretensión está concentrada en los efectos comunes para toda la clase de sujetos afectados y hay una clara afectación del acceso a la justicia, porque no se justifica que cada uno de los posibles afectados de la clase de sujetos involucrados promueva una demanda peticionando la inconstitucionalidad de la norma;

b) hubo una adecuada representación de todos los usuarios de los servicios de telecomunicaciones -dentro de los que se encuentran los abogados, por quienes específicamente además reclamaba el actor, por afectarse simultáneamente su intimidad como persona y los privilegios de confidencialidad entre abogados y clientes- a quienes se les extenderán los efectos de la sentencia;

c) se le dio una importante publicidad al asunto, en especial respecto de la audiencia celebrada, en la que participaron además, en apoyo de la pretensión del demandante, la Federación Argentina de Colegios de Abogados y el Colegio Público de Abogados de la Capital Federal, quie- nes comparecieron previamente como Amicus Curiae para evitar "las nefastas consecuencias que para todos los habitantes de nuestro país y en particular para los abogados matriculados en nuestro colegio traería aparejada la subsistencia formal de las normas cuestionadas";

d) ya se encontraba firme y fuera de discusión la declaración de inconstitucionalidad de la Ley 25.873, y el Decreto Reglamentario 1563/04 había sido suspendido en su vigencia;

e) el carácter erga omnes de la decisión halla fundamento no solo en la búsqueda, por parte del juzgador, de arbitrios tendientes a superar el escollo derivado de la arraigada concepción individualista en materia de legitimación (como se había afirmado en baja instancia), sino que se sustenta en la proyección superadora de la regla inter partes, determinante de la admisibilidad de la legitimación grupal, inherente a la propia naturaleza de la acción colectiva en virtud de la trascendencia de los derechos que por su intermedio se intentan proteger. Tal estándar jurídico reconoce su fuente primaria en el propio texto constitucional y, lejos de ser una construcción novedosa, aparece como una institución ya arraigada en el ordenamiento normativo vigente; en concreto se encuentran soluciones de la índole referida en las regulaciones especiales que instauran instrumentos de carácter colectivo para obtener reivindicaciones en materia de defensa a los usuarios y consumidores (art. 54, párrafo segundo, de la Ley 24.240) y en lo atinente a daño ambiental (art. 33, in fine, de la Ley 25.675). ${ }^{13}$

13 En este sentido, el art. 54, segundo párrafo, de la Ley de Defensa del Consumidor, expresa: "La sentencia que haga lugar a la pretensión 
Aplicando todas estas precisiones al caso del hábeas data colectivo y al hábeas data de clase, cabe además recordar que la doctrina ha propiciado al primero de estos desde la mismísima reforma constitucional de $1994^{14}$ y la Corte al segundo, una década y media más tarde, en Halabi, y que en definitiva el hábeas data colectivo debe poder ser incoado tanto por la persona registrada (cuando considera que además de ella existen otras personas afectadas igualmente por un tratamiento ilegal), como por ciertas asociaciones (vulgarmente conocidas bajo las siglas ONG) constituidas en pro de la defensa de determinados fines de bien común (v. gr., de lucha contra la discriminación, de defensa del consumidor, etc.) y por el defensor del pueblo (en virtud de su usual legitimación procesal a fin de tutelar judicialmente los derechos de las personas) e incluso por el Ministerio Público. Así, en estos tipos de hábeas data no se tutela ya un mero interés individual, sino el de muchas individualidades y a la vez uno general; por ello se acude a la representación colectiva, pero en el caso, estando vedado a estos otros legitimados distintos del afectado acceder directamente

hará cosa juzgada para el demandado y para todos los consumidores o usuarios que se encuentren en similares condiciones, excepto de aquellos que manifiesten su voluntad en contrario previo a la sentencia en los términos y condiciones que el magistrado disponga". De un modo semejante, el art. 33, in fine, de la Ley 25.675 dispone que "la sentencia hará cosa juzgada y tendrá efecto erga omnes, a excepción de que la acción sea rechazada, aunque sea parcialmente, por cuestiones probatorias".

14 Así, v. gr., Palazzi ha entendido que "no debe descartarse la posibilidad de ejercer una suerte de «hábeas data colectivo», en los casos de discriminación, lo que se ve posibilitado por una interpretación conjunta del párr. 2 del art. 43.

Al no hacer distinción, entendemos que se posibilita su ejercicio tanto a personas individuales como colectivas, pues donde la ley no distingue el intérprete tampoco debe hacerlo" (Palazzi, 1994, pág. 13). a los datos de terceros, en el caso solo el juez del hábeas data y en todo caso el funcionario legalmente legitimado podrán acceder a ellos si fuera necesario constatar su característica y eventualmente verificar su eliminación.

También de este sector de la norma puede detectarse una limitación respecto del objeto del hábeas data, ya que refiere solo a dos de las muchas facultades que pueden conferírsele al afectado -y lo mismo puede decirse de las acciones consecuentes a las que habilita luego al facultar al afectado a accionar sobre los datos a los cuales accediera-, pero esta restricción al radio de acción es solo aparente desde que en la jurisprudencia se ha articulado con otros fines, y que dieran lugar a la categorización doctrinal de los distintos tipos y subtipos de hábeas data a partir del variopinto de posibilidades de despliegue..$^{15}$

\section{D. "que consten en registros o bancos de datos públicos, o los privados destinados a proveer informes"}

En este sector de la norma se aborda la legitimación pasiva. La primera parte no presenta inconveniente alguno, salvo por la errónea denominación "bancos de datos públicos", desde que, como lo indica Peyrano (2002), la expresión

\footnotetext{
15 A este respecto, en un intento de categorización con fines didácticos, se han sistematizado los distintos tipos y subtipos del siguiente modo: a) Hábeas data informativo: subtipos localizador, exhibitorio, finalista y autoral; b) Hábeas data aditivo: subtipos actualizador, aclaratorio e inclusorio; c) Hábeas data rectificador; d) Hábeas data exclutorio o cancelatorio; e) Hábeas data impugnativo: subtipos opositor (de tratamientos) y objetor (de decisiones automatizadas); f) Hábeas data asegurador; g) Hábeas data reservador: subtipos confidencializador, disociador y encriptador; g) Hábeas data bloqueador y h) Hábeas data resarcitorio.
} 
correcta es "bancos públicos de datos", porque lo público en realidad no se pretendió predicar de los datos sino de los bancos de datos. En definitiva, se trata de "bancos de datos personales de titularidad pública" como de manera similar lo menciona la ley española.

El segundo sector de la norma es el que ha quedado totalmente superado por obra de la doctrina, de la jurisprudencia y de las normas reglamentarias, debiendo entenderse dicha limitación a los bancos de datos de titularidad privada como estrictamente ceñida a lo que refiere el Decreto 1558/01, reglamentario de la Ley 25.326, esto es, que solo quedan excluidos del radio de acción del hábeas data los bancos de datos que son de uso exclusivamente personal de su registrador, entendido este como persona física.

Debe aquí recordarse que para el caso de los sistemas de información de carácter privado, el tercer párrafo del art. 43 constitucional traza dos límites: a) los bancos de datos deben estar "destinados a proveer informes", y b) en caso de articulaciones contra bancos periodísticos "no podrá afectarse" el secreto de la fuente de información.

La primera referencia fue reproducida por el art. 1 de la LPDP al definir como objeto de la ley "la protección integral de los datos personales asentados en archivos, registros, bancos de datos, u otros medios técnicos de tratamiento de datos, sean estos públicos, o privados destinados a dar informes" y también por los arts. 33 y 35 , que norman, respectivamente, que la acción de protección de los datos personales o de hábeas data procederá respecto de "archivos, registros o bancos de datos públicos o privados destinados a proporcionar informes" y de "responsables y usuarios de bancos de datos públicos, y de los privados destinados a proveer informes".

A fin de interpretar correctamente los alcances de ambas normas, cabe recordar, como lo hace Sagüés (1995, pág. 680), que la previsión constitucional reproducida por la ley suscitó debate en la Asamblea Constituyente y que hubo incluso posiciones más restrictivas del radio de acción del hábeas data, en especial las de Cavagna Martínez y Cullen, que pretendían, respectivamente, limitar al hábeas data para el caso de los bancos de datos automatizados y en el caso de los privados destinados a proveer informes, que estos fueran "de uso público", pero que en definitiva lo importante no es que estos bancos estén destinados a proveer informes ni que de hecho los provean, sino que sean susceptibles de generar información personal, en la medida en que esta no sea de uso exclusivo de su registrador-persona física, ya que en tal caso ese banco de datos encuentra cobertura en el art. 18 de la Constitución nacional que protege los "papeles privados". ${ }^{16}$

16 Ver también su disertación en el Seminario Internacional sobre la Acción de Hábeas Data, celebrado en Talca, Chile, entre el 9 y el 11 de abril de 1997, donde expresó que la norma constitucional es, en síntesis, "por un lado amplio, porque basta que la base de datos esté destinada a proveer informes (aunque de hecho no los esté suministrando), para que pueda prosperar el hábeas data; pero por otro es en alguna medida restrictivo, ya que no es suficiente con que el registro privado sea «susceptible de generar información»: debe hallarse pensado para «proveer informes». Desde luego, la ley reglamentaria podría ampliar la órbita de actuación de este proceso constitucional. 
Ahora bien: la restricción legal apuntada se relativiza en la misma LPDP y en su decreto reglamentario, pues por una parte la LPDP no solo reglamenta el hábeas data constitucional sino que estatuye los principales derechos de registrantes y registrados al estilo de las leyes europeas, de modo que si bien se sujeta concretamente el acceso a los bancos de datos privados destinados a proveer informes, en el resto de los derechos no ocurre lo mismo. ${ }^{17}$

Además, en la misma norma aparecen previsiones que desdibujan la pretensión restrictiva plasmada en su art. 1, entre ellas, los arts. 3 y 24. El artículo 3 en cuanto declara ilícita a la formación de archivos de datos cuando estos no se inscriban ante el órgano de control o no observen en su operación los principios que establece la mencionada ley y las reglamentaciones que se dicten en su consecuencia. Y el artículo 24, que establece que los particulares que formen archivos, registros o bancos de datos que

De todos modos, queda claro que un registro privado es cuestionable por el hábeas data si provee informes a terceros, o si no los provee de hecho, pero está destinado a hacerlo.

Quedan fuera del hábeas data, eso sí, los archivos o registros de y para uso exclusivo de su propietario, ya que todo ello está amparado por el manto de privacidad que otorga el art. 19 de la Constitución, y por la inviolabilidad de los papeles privados, del art. 18.

Por último, conviene advertir que la Constitución no distingue en cuanto la estructura técnica del registro o banco de datos: podrá ser manual, mecánico, electrónico, computarizado o no, etc." (Sagüés, 1997, pág. 140)

17 Recuerda al respecto Uicich que "de acuerdo con la intención del legislador y dado el contexto general de la ley, la misma amplía su ámbito a aquellos bancos de datos privados que sin estar ab initio destinados a dar información, sin embargo proceden a hacerlo.

La legislación en la Unión Europea no limita el ámbito de protección de la ley a los bancos de datos privados "destinados a dar informes»" (2001, pág. 27). no sean para un uso exclusivamente personal deberán registrarse ante el órgano de control.

Las falencias de la restricción del radio de acción del instituto y su clara ajenidad a las normativas comparadas de protección de datos llevó a que al reglamentarse la ley, y concretamente en el art. 1 del Decreto 1558/01, se dispusiera que deben entenderse comprendidos en el concepto de archivos, registros, bases o bancos de datos privados destinados a dar informes, "aquellos que exceden el uso exclusivamente personal y los que tienen como finalidad la cesión o transferencia de datos personales, independientemente de que la circulación del informe o la información producida sea a título oneroso o gratuito", regla que entonces incluye tanto a los bancos de datos que de hecho provean informes aun cuando no estén destinados a ello o que en definitiva divulguen la información sin forma de informe.

En definitiva, habrá legitimación pasiva siempre que se verifique un supuesto de tratamiento que exceda del uso estrictamente personal en el sentido acordado a la garantía de inviolabilidad de los "papeles privados" acordada por el art. 18 de la Constitución nacional.

\section{E. "y en caso de falsedad o discriminación"}

Aquí la regla se refiere a los bienes jurídicos que pretende tutelar, y a tenor de su redacción pareciera establecer que una vez que el actor ha accedido a sus datos y conocido la finalidad del banco de datos, solo si se verificara falsedad de 
Ios datos o un efecto discriminatorio sobre el titular de estos, pueden exigirse ciertas operaciones sobre esos datos, pero tal conclusión es desacertada.

En efecto, en lo que atañe a los bienes jurídicos tutelados, el art. 43 constitucional ha ampliado el radio de cobertura de las acciones de garantía allí reguladas, de manera tal que cubre todos los derechos emanados de la Constitución, de un tratado o de una ley (en sintonía con lo exigido por la $\mathrm{CADH}^{18}$ ), correspondiéndole al amparo todos ellos salvo la libertad física (tutelada por el hábeas corpus en el art. 43, cuarto párrafo de la Carta Federal), e incluso en unas hipótesis algunos son más específicamente protegidos a través de sus subtipos especializados, como ocurre con el amparo colectivo y la acción de clase en su segunda versión de "defensa de los derechos constitucionales" detectada como implícita en el art. 43 por la Corte en Halabi (art. 43, segundo párrafo), y el hábeas data (art. 43, tercer párrafo).

En el caso concreto del hábeas data, si bien la Constitución nacional no enuncia expresamente los bienes jurídicos tutelados por esta especial acción, desde la literalidad del texto se previó que el instituto funcionara en los casos de "falsedad y discriminación", lo que permite inferir que, en una hipótesis de mínima, el objetivo de la figura es el de proteger el valor verdad y los principios dignidad, libertad e igualdad (los tres involucrados en el acto discriminatorio), pero ello obviamente es insuficiente, pues no solo

18 Convención Americana sobre Derechos Humanos. no se tradujo fielmente lo expresado en el seno de la Convención constituyente, sino que debió establecerse de manera expresa que el bien jurídico tutelado era el derecho a la protección de datos, que permite por su intermediación proteger cualquier derecho constitucional que pudiera estar conculcado, tal como surge claramente del variopinto de principios y derechos mencionados en los distintos votos emitidos por los integrantes de la Corte argentina en Urteaga. ${ }^{19}$

19 El texto finalmente aprobado por la Convención reformadora no coincide exactamente con lo sostenido en los debates habidos en ella, pues los convencionales aludieron a otros bienes jurídicos, entre ellos Ancarani, Cullen y Delich, que refirieron a varios bienes jurídicos tradicionalmente protegidos, y Cavagna Martínez, Hernández, Natale y Quiroga Lavié, que se enrolaron en la línea que lo limita al derecho a la intimidad. Incluso, en oportunidad de explicar los alcances de la norma proyectada, la convencional Roque, antes de considerar al hábeas data como un antídoto contra la discriminación laboral, cultural, artística, política o sindical (a las que definió como una verdadera defunción cívica), expresó que "si bien el bien jurídico tutelado es el derecho a la intimidad (...) la norma proyectada tiene la elasticidad y la amplitud conceptual que aconsejan las nuevas corrientes doctrinarias, permitiendo una legislación más ajustada a la hora de reglamentar, revalorizando al Congreso como factor de mediación social y política”.

El debate acerca del bien jurídico tutelado habido entre los convencionales se transfirió inmediatamente a la doctrina especializada y mientras Bergel, Bernales de Ruiz Vega, Bianchi, Ekmekdjian y Palazzi adhirieron a la tesis restrictiva al derecho a la intimidad, otros lo ampliaron a otros bienes, o bien no negaron que pudiera realizarse alguna extensión, como, v. gr., Bidart Campos. Badeni incluyó tanto a la intimidad como al honor; Guastavino lo aplicó solo a la protección del derecho a la identidad personal; Rivera lo extendió tanto a la identidad como a otros, Vanossi mencionó expresamente entre ellos al derecho a la imagen y Bazán aludió a un nuevo derecho, típico de esta figura, el "derecho a la autodeterminación informativa", rotulado por Leguisamón como "derecho de albedrío informático". En una posición semejante, Cifuentes aludió a la identidad, la intimidad, el honor y la imagen, y justificó la inclusión de esta última, ya que puede ser almacenada y trucada mediante las nuevas tecnologías

La cuestión a mi entender quedó zanjada por Sagüés, quien evaluando la problemática suscitada, y minimizando las consecuencias restrictivas que pudieran pretender adjudicársele a la fórmula escogida por el Constituyente, explicó: "Quizá por apresuramiento, el nuevo texto contempla el hábeas data para supuestos de «falsedad o discriminación», en custodia por ende de los valores verdad e igualdad; y no para otras hipótesis clásicas de esta figura, como la protección del honor o privacidad.

Este problema puede resolverse teniendo en cuenta que el amparo de la intimidad o el honor se vincula a menudo con la falsedad de datos o la discriminación; y que si así no fuera, una norma reglamentaria del hábeas data estaría habilitada para proyectarlo para aquellos 
La Ley 25.326 no resolvió finalmente el problema, pese a que se ampliaron desde lo expreso los bienes jurídicos tutelados, desde que se prevé en el art. 1 que la ley "tiene por objeto la protección integral de los datos personales... para garantizar el derecho al honor y a la intimidad de las personas, así como también el acceso a la información que sobre las mismas se registre" y se viabiliza a la acción para los casos en que "se presuma la falsedad, inexactitud, desactualización de la información de que se trata, o el tratamiento de datos cuyo registro se encuentra prohibido en la presente ley". La regla incurre en el error de referir al honor y a la intimidad, pero no conviene demasiado asir al instituto a solo un par de derechos y menos al derecho a la intimidad -aunque de este proviene-, pues ello, además de la innecesaria restricción de la figura, acarrearía eventualmente dos graves limitaciones en cuanto a la legitimación activa: si se entiende que no puede predicarse intimidad de las personas jurídicas o que esa intimidad no puede ser restaurada por los causahabientes del fallecido. ${ }^{20}$

derechos. Paralelamente, es posible concluir que si la privacidad y el honor son derechos de raigambre constitucional, deben lo mismo protegerse por el vehículo que sea necesario a tales fines, y que por ello el hábeas data no podría negarse en la especie. Tal extensión de la figura puede (y debe) consumarse incluso por la jurisprudencia" (1995, pág. 681).

20

En este aspecto, indica Bazán: "En conexión temática con la hipótesis planteada, un juez de la Corte Suprema de Justicia de la Nación (Vázquez) ha expresado, en su voto concurrente emitido en «Urteaga», que el derecho a la intimidad de las personas físicas no queda extinguido con su muerte «porque los vínculos familiares en cuyo marco todos los hombres desarrollan su vida de relación, hacen que aquel derecho subsista en la memoria que de las personas fallecidas conservan los parientes, para quienes toda invasión en la intimidad de aquél y en su buen nombre —que es el propio apelativo común- resulta lesivo de la intimidad familiar» (considerando 9).

Por la ruta contraria al pensamiento de Vázquez, Bidart Campos se pronuncia en desacuerdo con la existencia de un derecho a la intimidad
Frente a este cuadro, y definido que fuera por la doctrina, la jurisprudencia y las normativas más avanzadas que el bien jurídico que protege la acción de hábeas data es el nuevo y autónomo derecho a la protección de datos (y bien puede entenderse que al referir el art. 1 de la ley a la "protección integral de los datos personales", alude en definitiva a aquel derecho y que esa protección integral solo puede lograrse a través de un bien jurídico suficientemente abarcativo de todos los derechos que pudieran ser vulnerados a través de la lesión de aquel), cabe redefinir a los bienes jurídicos tutelados como todos aquellos que pueden ser resguardados a través del ejercicio de aquel -en los hechos, el abanico puede abarcar prácticamente todos los conocidos-, lo que puede hacerse mediante el ejercicio de los distintos derechos reconocidos al titular de los datos por la Constitución, la ley, la doctrina y la jurisprudencia habidas al respecto.

\section{F. "para exigir la supresión, rectificación, confidencialidado actualización de aquéllos"}

Este aspecto ya fue tratado supra, cuando se hizo referencia a la insuficiencia de la enumeración de las facultades que se conceden al afectado, y a la consecuente existencia de distintos

\footnotetext{
de las personas que mueren porque — sostiene- «los muertos no prolongan los derechos que titularizaron en vida, ni siquiera como subsistentes en la memoria de sus deudos; los derechos de estos podrán estar concatenados a los que fueron de la persona fallecida, pero serán derechos de quienes siguen viviendo, que se les reconocen en virtud del vínculo parental con el difunto. Eso y solo eso» (Bidart Campos, Germán J., ¿Hábeas data, o qué? ¿Derecho "a la verdad», o qué?, en "L.L." del 15/2/99, Suplemento de Derecho Constitucional, pág. 26, nota 11)” (Bazán, 2000, pág. 223).
} 
tipos y subtipos de habeas data que exceden la descripción realizada por el Constituyente.

Por ello resulta suficiente aquí con remarcar que no es necesario que exista falsedad o discriminación (pues basta con que se vulnere cualquiera de las reglas típicas del derecho de la protección de datos para activar la protección y brindar tutela a cualquiera de los bienes jurídicos que este derecho a la protección del dato puede proteger) para exigir cualquiera de las operaciones que sean necesarias para brindar esa protección, se encuentre o no en esta enumeración (v. gr., desindexar -por ejemplo, para ejercer el derecho al olvido en los buscadores-, encriptar -cuando confidencializar es insuficiente y se trata, por ejemplo, de datos vinculados a labores de inteligencia-, exigir la identificación de la fuente -siempre que con ello no se violara el derecho del periodista de mantener la confidencialidad de su informante-, etc.).

\section{G. "No podrá afectarse el secreto de las fuentes de información periodística"}

Tal como surge de lo que se indicó inmediatamente antes, existe un derecho a conocer de dónde obtuvo el dato quien lo está tratando, ello a fin de eventualmente poder accionar contra la fuente y evitar ulteriores reproducciones de la información dañosa, pero respecto de tal indagación hay una limitación emergente de esta última oración contenida en el párrafo bajo estudio.

Es que como regla general siempre puede indagarse acerca de la identidad del cedente de los datos, salvo que sea fuente de la información de un periodista, desde que, aunque el art. 35 LPDP no lo diga, la fuente de la información siempre es demandable, pues la doctrina ha encontrado, en el art. 43 in fine de la Constitución ("no podrá afectarse el secreto de las fuentes de información periodística"), interpretado a contrario sensu, que puede accionarse sobre cualquier fuente (hábeas data autoral) excepto cuando la información provenga de bancos de datos que constituyen fuente de información para los periodistas, y, desde luego, la reglamentación no puede negar una facultad proveniente de la Constitución.

La prohibición de revelar la identidad del autor (que en definitiva es la "fuente") de una información que es tomada por un periodista constituye en realidad una regla general (la confidencialidad de la fuente de información periodística) que trasciende a cualquier supuesto, esté o no en juego la información contenida en un banco de datos personales, y en este caso concreto ha encontrado una ampliación particular por vía reglamentaria, pues la LPDP amplió este supuesto en el art. 1, tercer párrafo, al sostener que tampoco podrán afectarse las bases de datos periodísticas: "En ningún caso se podrán afectar la base de datos ni las fuentes de información periodísticas". Dispone también la LPDP en el art. 40, ap. 1, que los registros, archivos o bancos de datos privados no podrán alegar la confidencialidad de la información que se les requiere "salvo el caso en que se afecten las fuentes de información periodística", cuestiones que merecen un análisis mucho más pormenorizado que excede el motivo de este trabajo, limitándonos 
aquí a referir que no puede entenderse en modo alguno que la exclusión alcanza a todos los supuestos de bancos de datos de las empresas periodísticas, pues estas ordinariamente llevan diversos tipos de bancos de datos personales que nada tienen que ver con la excepción (como en cualquier empresa, las de proveedores y clientes, las de sus empleados, etc.) y por ello deben entenderse excluidos de ella, que solo debe entenderse protectoria de la base de datos de un periodista individualmente considerado, mientras esta no esté interconectada pues allí sí excedería el uso personal de su registrador.

Por último, cabe hacer notar que existen otras restricciones implícitas a las facultades de los legitimados activos, que derivan de las normas reglamentarias de la cláusula constitucional y que son comunes en el derecho comparado, como por ejemplo la posibilidad de negar los accesos y demás operaciones conexas en los supuestos en que esté en juego, v. gr., la seguridad nacional.

En los debates habidos en el seno de la Convención Nacional Constituyente se abordó la cuestión de la posibilidad de acceder, vía hábeas data, a los registros de organismos de inteligencia del Estado, por ejemplo cuando Delich expresó:

A mucha gente le molesta el secreto de Estado y con razón, porque es evidente que cuanto más amplia es la zona del secreto, tanto más reducida es la zona de transparencia ligada a la construcción de la democracia en la sociedad. De modo que nadie podría hacer el elogio de la necesidad indefinida del secreto de Es- tado, pero también es cierto que nadie podría imaginar un Estado que no sea capaz de guardar y proteger esta zona oscura, muchas veces ligada a otra de las características del Estado moderno, que es la razón de Estado. Entonces, la única solución que tenemos -y es la que vamos a instrumentar con este instituto- no es pensar ni imaginar un Estado absolutamente carente de secreto. Lo que sí vamos a hacer es posibilitar que este secreto no sea para siempre. Este secreto está acotado. En la medida en que se funda en alguna necesidad, nadie puede imaginar que ella se prolongue para siempre. Tiene que haber un momento en el cual este secreto se decide racionalmente, y otro en el cual ese secreto es levantado. Entonces, nosotros no desprotegemos al Estado pero tampoco a la sociedad. No dejamos al Estado sin una herramienta decisiva, pero tampoco posibilitamos que un ciudadano esté indefenso frente a los secretos de Estado (...). Estamos demostrando que no existe una vigencia orwelliana, y que en el secreto de Estado no se incluye el derecho de decir cualquier cosa de cualquiera (sesión 12/08/94).

Esta exposición se fundó, en definitiva, en los lineamientos del art. 27 de la Constitución de San Juan, que -si bien se refiere estrictamente a las fuentes de información-, restringe el libre acceso a ella en asuntos vitales para la seguridad del Estado, pero a la vez ordena fijar por ley el tiempo de reserva.

Frente a la falta de reglamentación específica -como lo explicara Palazzi antes de la aprobación de la LPDP-, los organismos de inteligencia podían negarse a brindar o modificar los datos invocando la aplicación de la ley de defensa na- 
cional, por ser una excepción a la admisibilidad del amparo autorizada por el art. 2 de la Ley 16.986, pero ello no eximía a la juez del amparo de analizar la irrazonabilidad en el objeto del acto o en la finalidad perseguida por la Administración, con lo cual, solo si actuara justificadamente correspondería confirmar la decisión administrativa denegatoria del acceso a los datos (2004, pág. 17).

Al dictarse la Ley 25.326 se tomó en cuenta que la aplicación de restricciones a los derechos, por razones de este tipo, es común en el derecho extranjero, ${ }^{21}$ y por ello se incorporaron dos disposiciones precisas relacionadas con estos tipos de bancos de datos, en concreto alojadas en los arts. 17 (referido a las excepciones al derecho de acceso y a los demás derechos conexos) 22 y 23 (respecto a los supuestos espe-

21 Así, por ejemplo, la Constitución brasileña ha establecido el derecho a recibir de los órganos públicos informaciones de su interés particular, excepto aquellas cuyo sigilo sea imprescindible para la seguridad de la sociedad y del Estado (art. 5, numeral XXXIII); la de Portugal —al igual que en los casos de secretos de justicia- excepciona los derechos de rectificación y actualización otorgados por el hábeas data si ello está dispuesto en la ley sobre secreto de Estado.

Entre otros antecedentes provenientes del derecho comparado, Palazzi ha señalado que "la ley Federal de los Estados Unidos que regula el acceso a los registros públicos _ Freedom of Information Act-, contiene nueve excepciones y dentro de la primera de ellas se hallan contemplados los planes militares, las armas, las operaciones, información sobre gobiernos extranjeros, ciertos datos relacionados con la seguridad nacional y con materiales nucleares. La ley inglesa (art. 27) excluye el acceso a los datos cuando fuere necesario para la salvaguarda de la seguridad nacional. La ley española (arts. 21, incs. 1 y 2 y 22) también excluye ciertos datos relativos al secreto estatal" (1994, pág. 17).

22 "Art. 17 (Excepciones). 1. Los responsables o usuarios de bancos de datos públicos pueden, mediante decisión fundada, denegar el acceso, rectificación o la supresión en función de la protección de la defensa de la Nación, del orden y la seguridad públicos, o de la protección de los derechos e intereses de terceros.

2. La información sobre datos personales también puede ser denegada por los responsables o usuarios de bancos de datos públicos, cuando de tal modo se pudieran obstaculizar actuaciones judiciales o administrativas en curso vinculadas a la investigación ciales relacionados con los bancos de datos de las fuerzas armadas, fuerzas de seguridad, organismos policiales o de inteligencia). ${ }^{23}$

Las previsiones recién citadas advierten sobre la posibilidad de restringir, fundadamente, el derecho de acceso y los conexos en función de diversas causales claramente tipificadas: el acceso, cuando se pudiera obstaculizar actuaciones judiciales o administrativas en curso vinculadas a la investigación sobre el cumplimiento de obligaciones tributarias o previsionales, el desarrollo de funciones de control de la salud y del medio ambiente, la investigación de delitos penales y la verificación de infracciones administrativas; y los derechos conexos, cuando esté en juego la protección de la defensa de la $\mathrm{Na}$ ción, del orden y la seguridad públicos, o de la

sobre el cumplimiento de obligaciones tributarias o previsionales, el desarrollo de funciones de control de la salud y del medio ambiente, la investigación de delitos penales y la verificación de infracciones administrativas. La resolución que así lo disponga debe ser fundada y notificada al afectado.

3. Sin perjuicio de lo establecido en los incisos anteriores, se deberá brindar acceso a los registros en cuestión en la oportunidad en que el afectado tenga que ejercer su derecho de defensa."

23 "Art. 23.- (Supuestos especiales). 1. Quedarán sujetos al régimen de la presente ley, los datos personales que por haberse almacenado para fines administrativos, deban ser objeto de registro permanente en los bancos de datos de las fuerzas armadas, fuerzas de seguridad, organismos policiales o de inteligencia; y aquellos sobre antecedentes personales que proporcionen dichos bancos de datos a las autoridades administrativas o judiciales que los requieran en virtud de disposiciones legales.

2. El tratamiento de datos personales con fines de defensa nacional o seguridad pública por parte de las fuerzas armadas, fuerzas de seguridad, organismos policiales o inteligencia, sin consentimiento de los afectados, queda limitado a aquellos supuestos y categoría de datos que resulten necesarios para el estricto cumplimiento de las misiones legalmente asignadas a aquéllos para la defensa nacional, la seguridad pública o para la represión de los delitos. Los archivos, en tales casos, deberán ser específicos y establecidos al efecto, debiendo clasificarse por categorías, en función de su grado de fiabilidad.

3. Los datos personales registrados con fines policiales se cancelarán cuando no sean necesarios para las averiguaciones que motivaron su almacenamiento." 
protección de los derechos e intereses de terceros. Respecto de los bancos de datos llevados por las fuerzas armadas, fuerzas de seguridad, organismos policiales o inteligencia, establece un régimen diferenciado entre: a) datos almacenados de manera permanente con fines administrativos (v. gr., los laborales de sus empleados) y sobre antecedentes personales que se proporcionen a autoridades administrativas 0 judiciales (v. gr., los datos penales llevados por el Registro Nacional de Reincidencia) por las fuerzas armadas o de seguridad y por los organismos policiales y de inteligencia, a los cuales les aplica plenamente las previsiones de la ley, y b) los bancos de datos personales llevados con fines de defensa nacional o seguridad pública, donde limita los tratamientos a las categorías de datos que resulten necesarios para el estricto cumplimiento de las misiones legalmente asignadas a aquellos para la defensa nacional, la seguridad pública o para la represión de los delitos, agregando que los archivos, en tales casos, deberán ser específicos y establecidos al efecto, debiendo clasificarse por categorías, en función de su grado de fiabilidad. Por último, ordena la cancelación de los datos personales registrados con fines policiales cuando no sean necesarios para las averiguaciones que motivaron su almacenamiento.

Las restricciones emanadas de estas reglas pueden aparecer razonables, pero también en algún supuesto excesivas, pues no parece prima facie que el mero acceso a los datos propios pueda comprometer a la seguridad nacional aunque tal vez sí pueda hacerlo el permitir al sujeto activo operar sobre sus datos-, lo cual, des- de ya no cabe extenderlo a cualesquiera otros que puedan ser necesarios para salvaguardarla.

Así, si bien todo dependerá de la valoración que haga el juez de acuerdo con las circunstancias del caso y del momento histórico en que el hábeas data se articule, a los efectos de brindar un mayor o menor radio de acción a la garantía siempre debe reconocerse derecho de acceso a los datos propios, se trate del organismo que fuere, porque siempre la intromisión se limitará a verificar lo estrictamente personal.

Lo que sí podrán variar serán las demás facultades que puedan conferirse, es decir, lo que pueda o no hacer el interesado con los datos de acuerdo con la finalidad por la cual se han registrado; en tal caso, los medios de prensa y los organismos de inteligencia esgrimirán o no razones que justifiquen que esos datos permanezcan en sus archivos. Tal vez allí -y solo allílas facultades de estos serán más amplias que las de los demás registradores.

Desde el ángulo jurisprudencial, la Corte nacional se ha pronunciado sobre este tipo de datos, antes y después de la entrada en vigencia de la Ley 25.326.

Primigeniamente, y a falta de reglamentación, en Ganora (csjn, 16/9/99) exigió concretamente que la oposición del requerido sea fundada, acreditándose los extremos que hacen aplicable la excepción legal de acceso a la información, recordando que en Urteaga (csjn, 15/12/98) la amplitud de los alcances del hábeas data encuentra limitaciones, fundamentalmente, en 
razones de seguridad y defensa nacional, como está reconocido en el ámbito internacional, de modo que:

La obtención de información sobre datos personales obrantes en los organismos y fuerzas de seguridad halla adecuación legal en la acción de hábeas data; ello sin perjuicio de que el suministro de esa información pueda, eventualmente, afectar la seguridad, la defensa nacional, las relaciones exteriores o una investigación criminal, cuestión que en cada caso deberá ser invocada por el titular de la respectiva institución... la decisión del a quo de rechazar la acción deducida por considerar que los particulares no pueden tener acceso a la información obrante en las fuerzas armadas y organismos de seguridad del Estado 'por obvias razones de seguridad pública', constituye una afirmación dogmática carente de razonabilidad, pues al no haberse librado los oficios requeridos, no existe la respuesta pertinente del titular de la institución que haga saber si obra la información requerida y si existen razones que, en definitiva, pudieran impedir al legitimado acceder a ella (csjn, 16/9/99).

Del mismo modo, más recientemente, y ya vigente la Ley 25.326, en R.P., R.D. c/Estado Nacional -SIDE-s/Habeas data (csJn, 19/04/11), el alto tribunal confirmó la sentencia de segunda instancia que había hecho lugar a una demanda articulada contra el Estado Nacional, disponiendo que la Secretaría de Inteligencia del Estado (side) tiene el deber de informar al solicitante sobre sus datos personales contenidos en bancos de datos de inteligencia, y que solo puede negarse tal derecho en caso de protección de la defensa de la Nación, de intereses de terceros y de la seguridad pública, supuesto que no se configuraba puesto que la información la solicitaba el titular de los datos para cumplir con su trámite jubilatorio. La Corte rechazó el argumento esgrimido por el Estado, según el cual toda la información de inteligencia de la SIDE se halla contemplada en el art. 17 de la Ley 25.326, y este le permite libremente denegar el suministro de datos cuando pudiera afectarse la defensa de la Nación, el orden o la seguridad pública. Al respecto, señaló el Alto tribunal que excluir de la protección constitucional a esos datos que los organismos estatales mantienen fuera del acceso de los particulares comportaría la absurda consecuencia de ofrecer una acción judicial solo en los casos en los que no es necesaria, y que el límite a la posibilidad de acceder a la información está dado en ciertas circunstancias específicas, tales como el carácter de las funciones que desarrolla la SIDE o cuando esté en juego la protección de la defensa nacional, la seguridad pública o la represión de delitos, según lo previsto en el art. 17 , incs. $1^{\circ}$ y $2^{\circ}$, de la Ley 25.326, lo que debe ser específicamente invocado por el titular de la dependencia requerida, ya que además la Ley 25.520 (Ley de Inteligencia Nacional) no altera lo dicho, en tanto estableció que el Sistema de Inteligencia Nacional debía ajustarse estrictamente a la Constitución nacional y a las normas legales vigentes.

Entonces - concluyó el tribunal cimero-, al margen de que la actividad de inteligencia nacional consista en la obtención, reunión, sistematización y análisis de la información específica referente a hechos, amenazas, riesgos y conflictos que afecten la seguridad exterior o interior de 
la Nación, toda denegación de acceso de datos debe estar fundada en los motivos señalados en el mencionado artículo 17 de la Ley 25.326. Además, la Ley de Inteligencia Nacional limita el tratamiento de los datos personales a los supuestos en que sea estrictamente necesario para el cumplimiento de las misiones legalmente asignadas, y ordena a los organismos de inteligencia enmarcar inexcusablemente sus actividades dentro de las prescripciones de la LPDP. ${ }^{24}$

\section{CONCLUSIONES}

A veinte años de la consagración constitucional del hábeas data (que el constituyente prefirió no llamarlo así y al cual el legislador le adosó como alias "acción de protección de los datos personales"), poco ha quedado incólume del tercer párrafo del art. 43, que actualmente en la práctica sirve solo como una mera referencia

24 Sostuvo expresamente el fallo, en lo que resulta de interés: "2) Que, tal como se concluye en el dictamen, las normas aludidas confieren al actor el derecho de obtener toda la información que pueda existir en la Secretaría de Inteligencia y sea útil para acceder al beneficio jubilatorio que invoca.

$\left.3^{\circ}\right)$ Que, sin embargo, para que tal derecho tenga efectiva concreción, la Secretaría se encuentra obligada a manifestar si tiene o no los datos requeridos; y si los tuviese solo podría negarse a revelarlos en los términos del artículo 17 , incisos $1^{\circ}$ y $2^{\circ}$, de la Ley 25.326 , vale decir, mediante "decisión fundada (...) en función de la protección de la defensa de la Nación, del orden y la seguridad pública, o de la protección de los derechos e intereses de terceros". Por su parte, los jueces cuentan con la potestad de verificar, a instancias del interesado, si las razones dadas por el organismo justifican la negativa a suministrar la información, para lo cual podrán "tomar conocimiento personal y directo de los datos solicitados asegurando el mantenimiento de su confidencialidad" (artículo 40 , inc. $2^{\circ}$, de la ley aludida); confidencialidad o secreto que también imponen los artículos 17 de la Ley 25.520 y 12 del decreto 950/2002.

$\left.4^{\circ}\right)$ Que a lo expuesto cabe añadir que la clasificación de la información de los organismos de inteligencia (artículos 23 , inc. $2^{\circ}$, de la Ley 25.326 y 16 de la Ley 25.520) no es óbice para que los jueces, a pedido de parte, puedan verificar si está comprometido el interés público y hacer efectiva la garantía del hábeas data (artículo 43, tercer párrafo de la Constitución Nacional)". normativa acerca de la existencia de un derecho a proteger los datos personales a través de un tipo especial de amparo (ello pese a que en su origen, en la Constitución del Brasil de 1988 era claramente un tipo asociado al hábeas corpus y no al mandado de segurança) y cuyo contenido ha sido modificado por una nutrida labor legislativa, doctrinaria y jurisprudencial.

En efecto, respecto del contenido literal del texto, sigue siendo cierto: que toda persona (física o de existencia ideal pero no solo la titular de los datos, sino también sus sucesores y otros legitimados no mencionados en el párrafo, como el defensor del pueblo, el Ministerio Público y las asociaciones sectoriales) puede interponer esta acción; que aunque tal acción tiene ribetes propios que la diferencian bastante de los amparos regulados en los dos párrafos anteriores, se nutre de ellos en lo que no luce incompatible; que la acción debe ser expedita y el proceso debe ser rápido, tal como lo reclama el primer párrafo del art. 43; que se encuentran legitimados pasivamente tanto los sistemas de información de titularidad pública como los de titularidad privada, en este último caso sin que rija la limitación en cuanto a que deban estar destinados a proveer informes, y con el tope de inoperabilidad respecto de bancos de datos de uso exclusivamente personal de su registradorpersona física.

Sin embargo, la acción en modo alguno está ya limitada para tomar conocimiento de los datos personales almacenados y de su finalidad, ni para la supresión, rectificación, confidencialidad o actualización de aquellos, sino que se 
puede utilizar para ejercer cualquier otra facultad emergente expresa o implícitamente de las estandarizadas reglas del derecho de la protección de datos personales respecto de los legitimados pasivos que las incumplan. Ello, claro está, respetando los topes constitucionales y legales que fueren razonables, como la prohibición -constitucional y legal- de afección del secreto de la fuente de información periodística y otras emergentes de la Ley 25.326 y de su decreto reglamentario.

Para la Argentina, la incorporación en orden constitucional de la acción de hábeas data ha resultado un formidable acierto, pues su fenomenal despliegue a lo ancho y a lo largo del país, por efecto de su operatividad directa, ha permitido en la práctica complementar muy eficazmente $-\mathrm{y}$ en muchos casos directamente suplantar- el insuficiente control administrativo previsto en la Ley 25.326 y su decreto reglamentario. Su eficacia protectora tal vez sea la principal razón por la cual la Comunidad Europea no ha revocado su carácter de país extracomunitario con nivel adecuado de protección a los efectos de la transferencia internacional de datos personales, del cual goza desde 2003. ${ }^{25}$

25 En el dictamen del Grupo de Trabajo del art. 29 de la Directiva 95/46/ CE, de 2002 (ver http://europa.eu.int/comm/internalmarket/en/dataprot/ wpdocs/index.htm), al evaluarse la situación de la Argentina frente al tratamiento de datos (lo que implicó valorar tanto la compatibilidad de sus normas, su doctrina y su jurisprudencia, como el plano fáctico), se aconsejó otorgarle el estatus de país extracomunitario con nivel de protección adecuado a los fines de la transmisión internacional de datos, pero tal carácter no le fue concedido sin reservas, pues se objetó, por un lado, la ausencia - por entonces total y por cierto hoy todavía predominante- de órganos de control de los estados federados, y, por el otro, la falta de independencia del órgano de control nacional —este aspecto solo se consideró respecto de la normativa vigente, pues poco podía evaluarse sobre su desempeño dado que apenas estaba comenzando a funcionar-, toda vez que la Ley 25.326 encomendó tal rol a una mera dirección, la Dirección Nacional de
Referencias

Bazán, V. (2000). El hábeas data y sus peculiaridades frente al amparo. Revista de Derecho Procesal, (4).

Bianchi, A. (2000). La nueva ley de protección de datos personales. Disertación pronunciada en las VI Jornadas Argentinas de Derecho Procesal Constitucional.

Bidart Campos, G. (1997). ¿Hábeas data, o qué? ¿Derecho "a la verdad", o qué? Suplemento de Derecho Constitucional, (26).

Bidart Campos, G. (1997). Los procesos constitucionales: amparo, hábeas data y hábeas corpus. XIX Congreso Nacional de Derecho Procesal. Corrientes.

Convención Nacional Constituyente. Sesión del 12/08/94. Versión taquigráfica.

Corte Suprema de Justicia de la Nación. (15/12/98). Urteaga, Facundo Raúl c/Estado Nacional -Estado Mayor Conjunto de las F.F.A.A.- s. Amparo ley 16.986. Fallos: 321: 2767, voto del Dr. Petracchi.

Corte Suprema de Justicia de la Nación. (16/9/99). Ganora, Mario F. y otra s/hábeas corpus. JA, 2000-II-43.

Protección de Datos, a la que ubicó en la estructura administrativa del Poder Ejecutivo, resultando un apéndice de la Secretaría de Justicia y Asuntos Legislativos (hoy de la Subsecretaría de Asuntos Registrales de la Secretaría de Justicia), a su vez dependiente del Ministerio de Justicia y Derechos Humanos. 
Corte Suprema de Justicia de la Nación. (5/4/05). Martínez, Matilde Susana c/ Organización Veraz S. A. M. 422. XXXVII, “J.A.” 2005-III-31.

Corte Suprema de Justicia de la Nación. (24/02/2009). Halabi, Ernesto c/ P.E.N. ley 25873 dto. 1563/04. Fallos, 332:111.

Corte Suprema de Justicia de la Nación. (03/06/2011). Lascano Quintana, Guillermo V. c/ Veraz S.A. s/ hábeas data, Fallos 324:567, voto de la mayoría, integrada por Moliné O'Connor, Belluscio, Petracchi, Boggiano, López y Bossert.

Corte Suprema de Justicia de la Nación. (19/04/11). R. P., R. D. c/ Estado Nacional Secretaría de Inteligencia del Estado. R. 755. XLIV. Recurso de hecho.

Corte Suprema de Justicia de la Nación. (19/08/99). Fayt, Carlos S. c/Estado nacional s/proceso de conocimiento (LL, 1999-E305, y ED, 184-998. Fallos, 251:132

Carranza Torres, L. (2001). Hábeas data: la protección jurídica de los datos personales. Córdova: Alveroni Ediciones.

Gelli, M. A. (2003). Constitución de la Nación Argentina (Segunda ed.). Buenos Aires: La Ley.

Vanossi, J. (Marzo, 1988). Un caso de hábeas data: entre el derecho procesal y el derecho constitucional. El Derecho, (9462), 1.

Masciotra, M. (2003). El hábeas data. La garantía polifuncional. La Plata: Editorial Platense.
Palazzi, P. (1994). El hábeas data en la Constitución nacional (La protección de la privacidad en la "era de la información"). La Ley.

Palazzi, P. (Noviembre, 1998). El hábeas data en el derecho argentino. Revista de Derecho Informático, (4). Obtenido de alfa-redi: http:// www.alfa-redi.org/rdi-articulo.shtml?x=179.

Peyrano, G. (2002). Régimen legal de los datos personales y hábeas data. Buenos Aires: LexisNexis/Depalma.

Puccinelli, O. (2004). Protección de datos de carácter personal. Buenos Aires: Astrea.

Ruiz Martínez, E. (1998). Los informes comerciales y el derecho a la información. Buenos Aires: Abaco.

Sacristán, E. (2007). Hábeas data: el origen de una especie. En J. C. Cassagne, Derecho Procesal Administrativo (t. II). Buenos Aires: Hammurabi.

Sagüés, N. (1995). Acción de amparo. Buenos Aires: Astrea.

Sagüés, N. (2009). Compendio de derecho procesal constitucional. Buenos Aires: Astrea.

Salgado, A. J., Verdaguer, A. C. (2000). Juicio de amparo y acción de inconstitucionalidad (2da. ed.). Buenos Aires: Astrea.

Uicich, R. (2001). Hábeas data. Ley 25.326. Buenos Aires: Ad hoc. 